\title{
Numerical Calculation of the Three-Dimensional Swirling Flow Inside the Centrifugal Pump Volutes
}

\author{
E. Cezmi Nursen and Erkan Ayder \\ Istanbul Technical University, Faculty of Mechanical Engineering, Hydraulic Machinery Division, \\ Taksim, Istanbul, Turkey
}

The flow inside the volute of a centrifugal pump is threedimensional and, depending upon the position of the inlet relative to the cross-section center line, a single or double swirling flow occurs. The purpose of this study was the calculation of the three-dimensional swirling flow inside the centrifugal pump volute.

The developed flow solver provides detailed pressure and velocity distribution information inside the volute, and the calculated results are verified by means of the experimental results presented in the literature.

Three-dimensional continuity and momentum equations are solved by means of an artificial compressibility technique. The finite volume approach is applied for space discretization, and an explicit fourth-order modified RungeKutta scheme is used for time discretizetion.

Calculations are performed at three different mass flows, one of which corresponds to the design's point mass flow. The calculated volute flow conditions-namely, the variation in static pressure and total pressure and the throughflow and swirling component of the flow velocity over the cross-sections, which are located at various circumferential positions-are compared with the experimental data in detail, and they exhibit a good agreement with the measured flow field.

Keywords Centrifugal pump, Computational fluid dynamics, Swirling flow, Volute

The function of the volute in a centrifugal pump or compressor is to collect the fluid coming out from the impeller and to deliver it to the discharge chamber with minimum losses.

Received 25 June 2002; accepted 1 July 2002.

Address correspondence to Erkan Ayder, Faculty of Mechanical Engineering, Hydraulic Machinery Division, Gumussuyu, Taksim, Istanbul, TR-80191, Turkey. E-mail: erkan@mkn.itu.edu.tr
Quite a large number of geometrical parameters have an influence on the volute's performance. Volutes designed by means of various design alternatives give different efficiencies and pressure ratios. The circumferential pressure distortion caused by the volute at off-design conditons may influence the flow inside the impeller and alter the performance of the impeller. In addition, it creates radial forces acting on the impeller shaft and may result in the failure of the bearings.

Nonuniform flow conditions at the volute inlet can propagate up to the impeller inlet where they induce instabilities and initiate surge.

The operating range of a pump or compressor becomes wider with circumferentially more uniform static pressure distribution.

The influence of the volute's geometrical parameters (like the shape of the volute cross-section, the circumferential variation of the cross-sectional area, and the radial position of the volute cross-section) on the global volute performance were studied by Mishina and colleagues (1978). The results showed that the internal type of volute, which has a cross-section center radius that is smaller than the diffuser's exit radius, has a very high loss coefficient compared to the other types. Global performance measurements indicate that a volute with a circular cross-sectional shape corresponds with minimum losses when compared to rectangular volutes.

The results of detailed flow measurements inside different types of compressor and pump volutes carried out by Hubl (1975), Van den Braembussche and colleagues (1990, 1999), Ayder and colleagues (1991), Ayder (1993), and Elholm and colleagues (1992) show that the three-dimensional swirling flow has a form of wrapping layers of nonuniform total pressure and reveals the basic loss mechanisms inside the volutes. Because of the dissipation of the kinetic energy at the center of the swirl, low-energy fluid accumulates at the centers of the cross-sections. In addition, the static pressure gradient pushes the fluid of low energy created in the boundary layers toward the center of the swirl.

Because of the nonuniform total pressure distribution at the volute inlet and the forced vortex type of distribution of the 
swirling velocity, the potential-flow equations cannot be used to analyze the flow inside a volute. Ayder (1993) calculates flow inside a compressor volute with an elliptical cross-section by solving the three-dimensional compressible Euler equations modified by the loss model. The results show that the developed model accurately predicts the velocity and pressure distribution inside the volute. A similar model is used by Hagelstein and colleagues (2000) for flow calculations inside the external volute of rectangular cross-sections.

The aim of the present study was to develop an incompressible flow solver for the pump volute and to evaluate it by means of the experimental data that exist in the litearature.

\section{FLOW MODEL AND NUMERICAL METHOD}

Three-dimensional continuity and momentum equations describing the inviscid incompressible flow are written in conservative form, as follows:

$$
\frac{\partial \vec{U}}{\partial t}+\frac{\partial \vec{F}}{\partial x}+\frac{\partial \vec{G}}{\partial y}+\frac{\partial \vec{H}}{\partial z}=0
$$

The vector $\vec{U}$, which consists of unknown variables and flux vectors $\vec{F}, \vec{G}$, and $\vec{H}$ in Equation (1) are:

$$
\begin{aligned}
\vec{U} & =\left[\begin{array}{c}
p / \rho_{0} \\
u \\
v \\
w
\end{array}\right] \vec{F}=\left[\begin{array}{c}
c^{2} u \\
u^{2}+p / \rho_{0} \\
u v \\
u w
\end{array}\right] \vec{G}=\left[\begin{array}{c}
c^{2} v \\
u v \\
v^{2}+p / \rho_{0} \\
v w
\end{array}\right] \\
\vec{H} & =\left[\begin{array}{c}
c^{2} w \\
u w \\
v w \\
w^{2}+p / \rho_{0}
\end{array}\right]
\end{aligned}
$$

where $c$ corresponds to the pseudospeed of sound and is described in the pseudocompressibility approach (Chorin, 1967).

All the flow properties are nondimensionalized by using the stagnation pressure $\left(\bar{P}_{0}\right)$, density $\left(\bar{\rho}_{0}\right)$, and impeller exit radius $\left(\bar{R}_{0}\right)$ in the following way:

$$
\begin{aligned}
L & =\frac{\bar{L}}{\bar{R}_{0}} \quad p=\frac{\bar{p}}{\bar{P}_{0}} \quad t=\frac{\bar{t}}{\bar{R}_{0}} \sqrt{\bar{P}_{0} / \bar{\rho}_{0}} \\
u, v, w & =\frac{\bar{u}, \bar{v}, \bar{w}}{\sqrt{\bar{P}_{0} / \bar{\rho}_{0}}}
\end{aligned}
$$

The space discretization is done by means of hexahedrons in which the flow quantities are described at the corners. The control volume, for which the integral form of Equation (1) is applied, consists of eight hexahedrons leading to the central type of space discretization.
The governing equations are solved explicitly by means of the finite volume technique and the time-marching approach. The time discretization is done by using the modified four-step Runge-Kutta scheme.

The artificial viscosity, which is required for the central type of discretization so as to stabilize the solution method, is determined as being proportional to the fourth-order differences of the conservative variables. The proportionality coefficient is equal to 0,004 . The dissipation term is calculated only at the first step and is kept constant for the other three steps of the Runge-Kutta scheme.

The implicit residual averaging applied in the second and fourth steps of the Runge-Kutta scheme provides the use of a larger Courant-Friedrichs-Lewy (CFL) number and that leads to better convergence characteristics.

\section{Boundary Conditions \\ Inlet Boundary}

As a result of the theoretical analysis of the solution method of three-dimensional incompressible Euler equations, three physical quantities are fixed at the volute inlet. Total pressure and two flow angles (between radial and tangential and the radial and axial components of the velocity) are imposed at the inlet plane of the calculation domain. The fourth one, the radial velocity, is determined from the interior domain by means of second-order extrapolation.

\section{Outlet Boundary}

One quantity has to be fixed by the physical flow condition at the outlet of the flow domain while the remaining three are determined by the interior conditions through numerical boundary conditions. The most appropriate physical condition is fixed downstream static pressure. Due to the swirling flow, the outlet static pressure is not uniform and therefore it is fixed at one point (the reference point) of the exit plane. The pressure ratio between the reference point (iref, jref, kmax) and an upstream point (iref, jref, kmax - 1) is first calculated by

$$
\text { Ratio }=\frac{p^{*}(\text { iref }, \text { jref }, \text { kmax })}{p(\text { iref }, \text { jref }, \text { kmax }-1)}
$$

and the pressures at other points of the exit plane are calculated by using the calculated ratio defined by Equation (3) and the pressure at the corresponding point in the previous plane:

$$
p(i, j, \max )=\text { Ratio.p }(i, j, \operatorname{kmax}-1) .
$$

\section{Solid Wall}

The nonpermeability condition is satisfied at the solid surfaces. At the corners of the volute with the rectangular crosssectional shape, the swirling component of the flow velocity is set equal to the zero during the calculation procedure because 


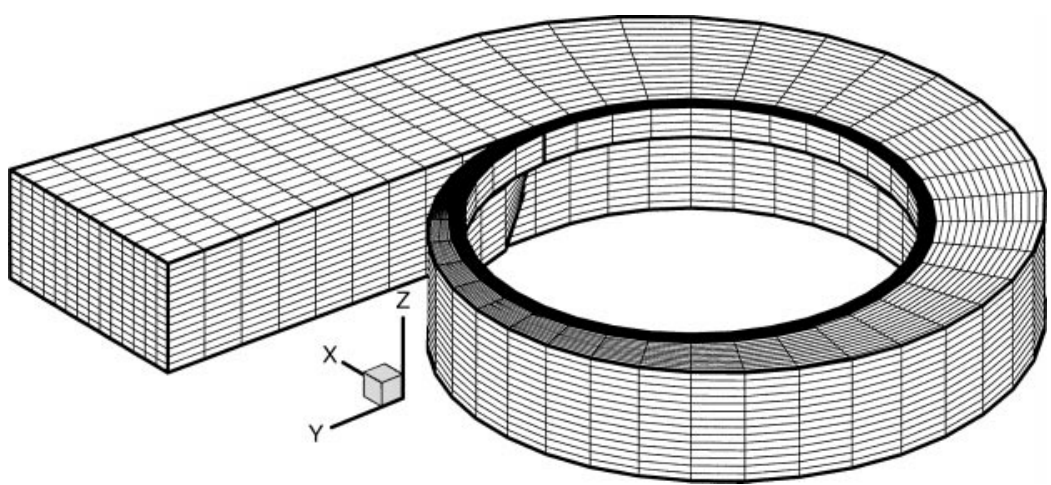

FIGURE 1

Volute geometry and generated mesh for the calculations.

the velocity cannot be tangential to the two separate directions at the corners.

\section{COMPARISON OF EXPERIMENTAL AND CALCULATED RESULTS}

The geometry of the volute and the generated mesh that is used in the calculations is shown in Figure 1. The volute is an external type with a rectangular cross-sectional shape having a constant axial width $(55 \mathrm{~mm})$. The inner wall of the volute has a constant radius $(0.106 \mathrm{~m})$ and the outer wall has a logarithmic spiral shape. A vaneless diffuser with a 6-mm radial length is located upstream of the volute.

The experimental measurements have been carried out inside the above-mentioned pump volute by Ayder (1993) and Elholm and colleagues (1992). The circumferential variation of static pressure at the volute inlet, the distribution of the swirling velocity at two cross-sections and the distribution of the through-flow velocity at four cross-sections have been measured at three mass flow rates, which are $0.0029 \mathrm{~m}^{3} / \mathrm{sec}$, $0.0045 \mathrm{~m}^{3} / \mathrm{sec}$, and $0.0062 \mathrm{~m}^{3} / \mathrm{sec}$, and have been labeled as low, medium and high flow rates, respectively, in the present study.

The generated mesh for the volute and exit pipe consists of $15 \times 15$ nodes on each of the 47 cross-sections. The vaneless diffuser is discretized by means of $6 \times 15$ grid points in 37 cross-sections (see Fig. 1).

A special connection is required at the tongue. The first cross-section is connected to the volute tongue, which is located at the diffuser exit. Since the volute tongue is a line along the volute's width, the surfaces of the first cross-sections are connected to the lines, and the three-dimensional discretization elements therefore become triangular prisms instead of hexhahedrons.

The comparisons of the measured and calculated circumferential variations of the static pressure at the volute are shown in Figure 2 for the three flow rates.
Four cross-sections on which detailed comparisons of the calculated and measured flow velocities were performed are shown in Figure 3.

For low flow rate, the static pressure increases from the volute tongue to the volute exit at the volute inlet. This results from the decelerating flow occurring inside the volute channel, which is predicted by the calculations (Fig. 4).

For medium flow rate, the static pressure is approximately constant at the volute inlet (see Fig. 2) and inside the volute channel (see Fig. 4).

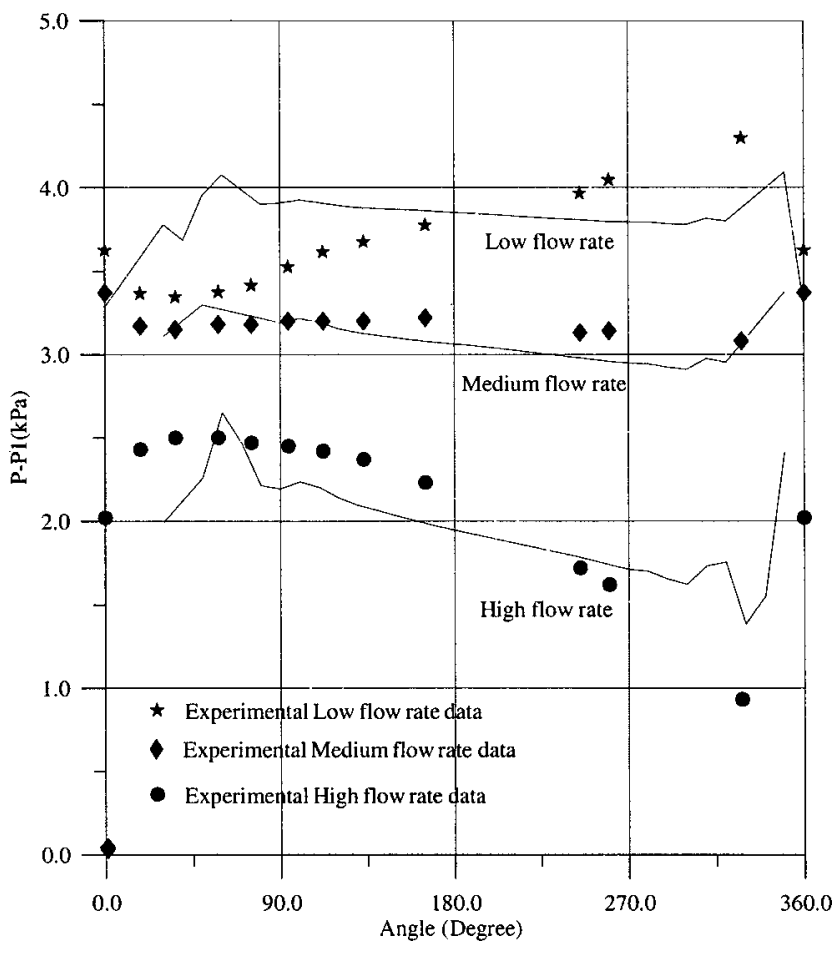

FIGURE 2

Comparison of the calculated and measured circumferential static pressure variations at the volute inlet. 


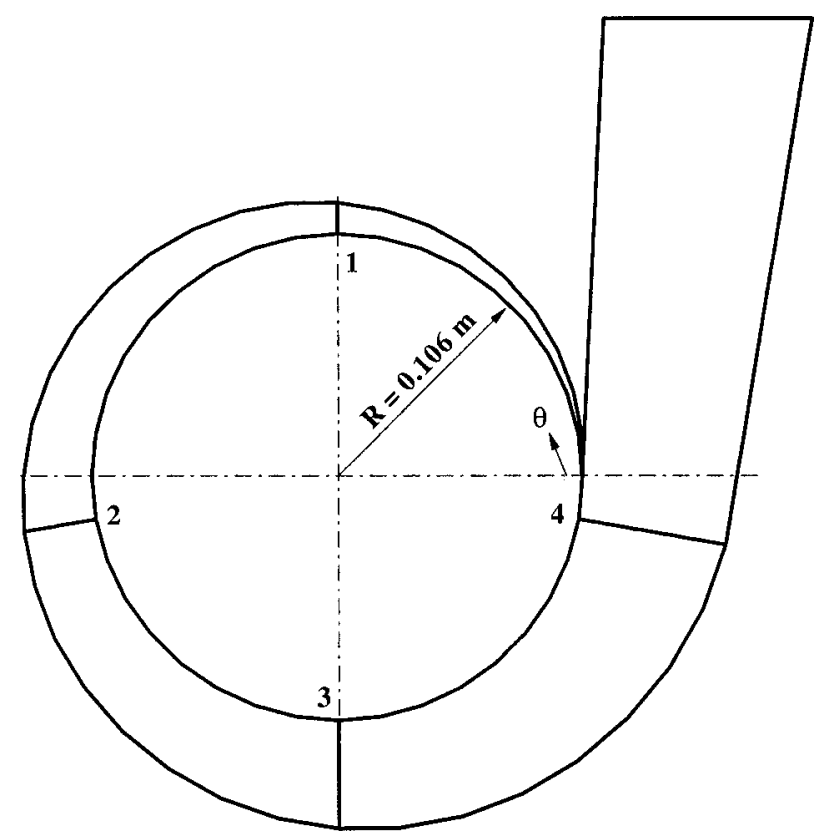

FIGURE 3

Positions of the cross-sections on which comparisons were performed.

For high-mass flow rate, the static pressure decreases from the volute tongue to the volute exit at the volute inlet (see Fig. 2) and inside the volute channel (see Fig. 4).

The calculated and measured circumferential variation of the static pressures at the volute inlet are in agreement for medium flow rate (see Fig. 2). Due to the flow disturbance caused by the volute tongue at off-design flow rates and the short length of the vaneless diffuser, the specified inlet boundary conditions may be different from the real flow conditions. This could be the major reason for the discrepancy between the calculated and measured circumferences of static pressure at low and high flow rates given in Figure 2.

The swirl velocities were measured only over sections 2 and 4 . The measurements show that swirling flow has a forced-vortex type of velocity distribution, and the calculated swirl velocities are in agreement with the measured velocities (Figs. 5A and 5B). The swirl center, however, is shifted toward the internal wall of the volute in the calculation at section 4. A small portion of the fluid separates from the main swirl due to increasing pressure in the radial direction for all three mass flows. Section 4 is very close to the volute tongue and, therefore, highly influences the pressure gradient around the tongue. In the case of high mass flow, high pressure occurring at the begining of the volute channel pushes the fluid toward the exit pipe under the tongue. Experimental results show that the swirl is therefore pushed toward the exit wall of the volute (see Fig. 5B). In the case of medium mass flow, no pressure gradient occurs around the tongue region, so the swirl center is located at the

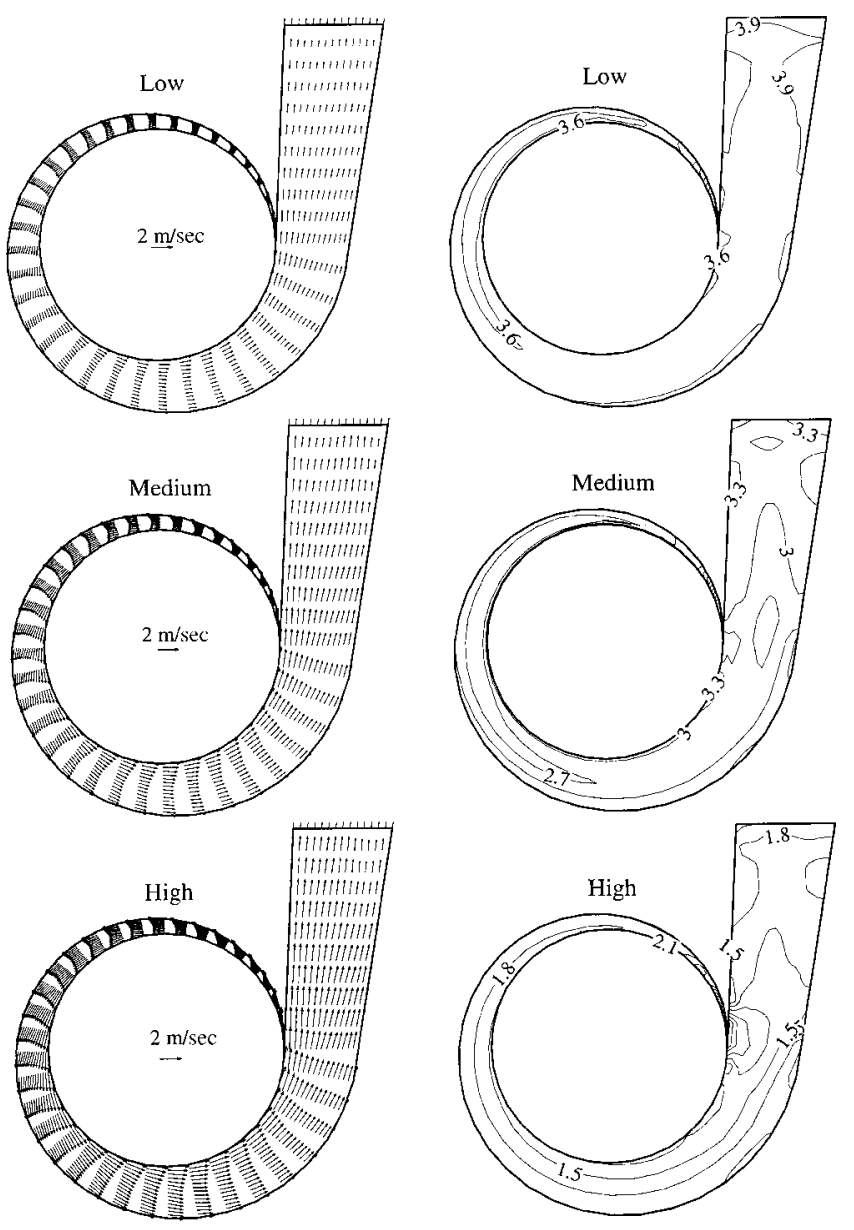

FIGURE 4

Calculated flow velocity and static pressure isolines in the volute and exit pipe for low, medium, and high flow rates.

center of the cross-section. The calculations cannot capture this phonemenon because of assumptions made in the modeling of the volute's geometry. The volute's tongue is represented as a line in the generated geometry and does not allow any flow through it, whereas in the real geometry, it has a finite thickness. The influence of this assumption is also seen on the throughflow variations over the cross-sections at low and medium flow rates.

In the case of a low flow rate, because of the increasing pressure from the exit pipe toward the volute's starting region, some amount of the fluid is pushed to the volute under the tongue and that increases the through-flow velocities inside the first cross-sections of the volute. The volute gap is modeled as a line in the calculations, so the calculated through-flow velocities at section 1 are smaller than the measured ones (Fig. 6A).

For high and medium flow rates, the calculated and measured through-flow velocities are compared over the four crosssections of the volute in Figures 6C and 6B, respectively. 

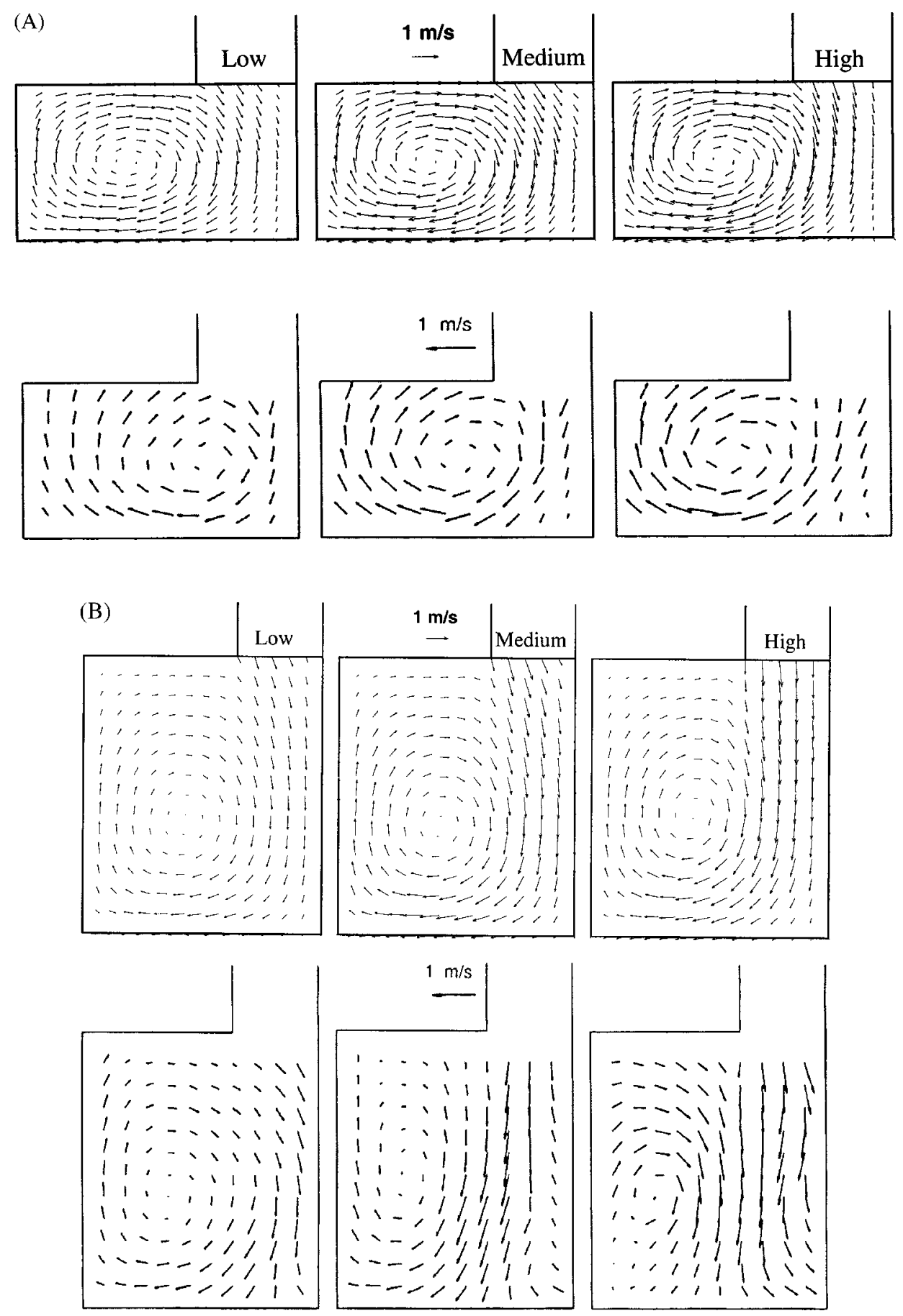

FIGURE 5

(A) Comparison of the swirl velocity distributions at cross-section 2, corresponding to low, medium, and high flow rates for numerical and experimental studies, respectively. (B) Comparison of the swirl velocity distributions at cross-section 4, corresponding to low, medium, and high flow rates for numerical and experimental studies, respectively.

The low through-flow velocities are calculated at the swirl center inside the exit pipe for all mass flows (see Fig. 4). This might be due to the accumulation of losses and therefore to the low-energy fluid at the swirl center.

\section{CONCLUSIONS}

The calculated and measured variations in the flow velocities inside a pump's volute are in good agreement. Because of assumptions made in the geometrical modeling of the 
volute tongue, some minor differences between the calculated and measured results were observed. More detailed modeling of the tongue's geometry might lead to better results.

In addition, the volute inlet conditions (the distribution of the total pressure, radial velocity, and through-flow velocity) were not measured experimentaly, and total pressure and flow angles were assumed in the calculations to be circumferentialy uniform at the volute inlet. This might also cause the difference between the calculated and measured results
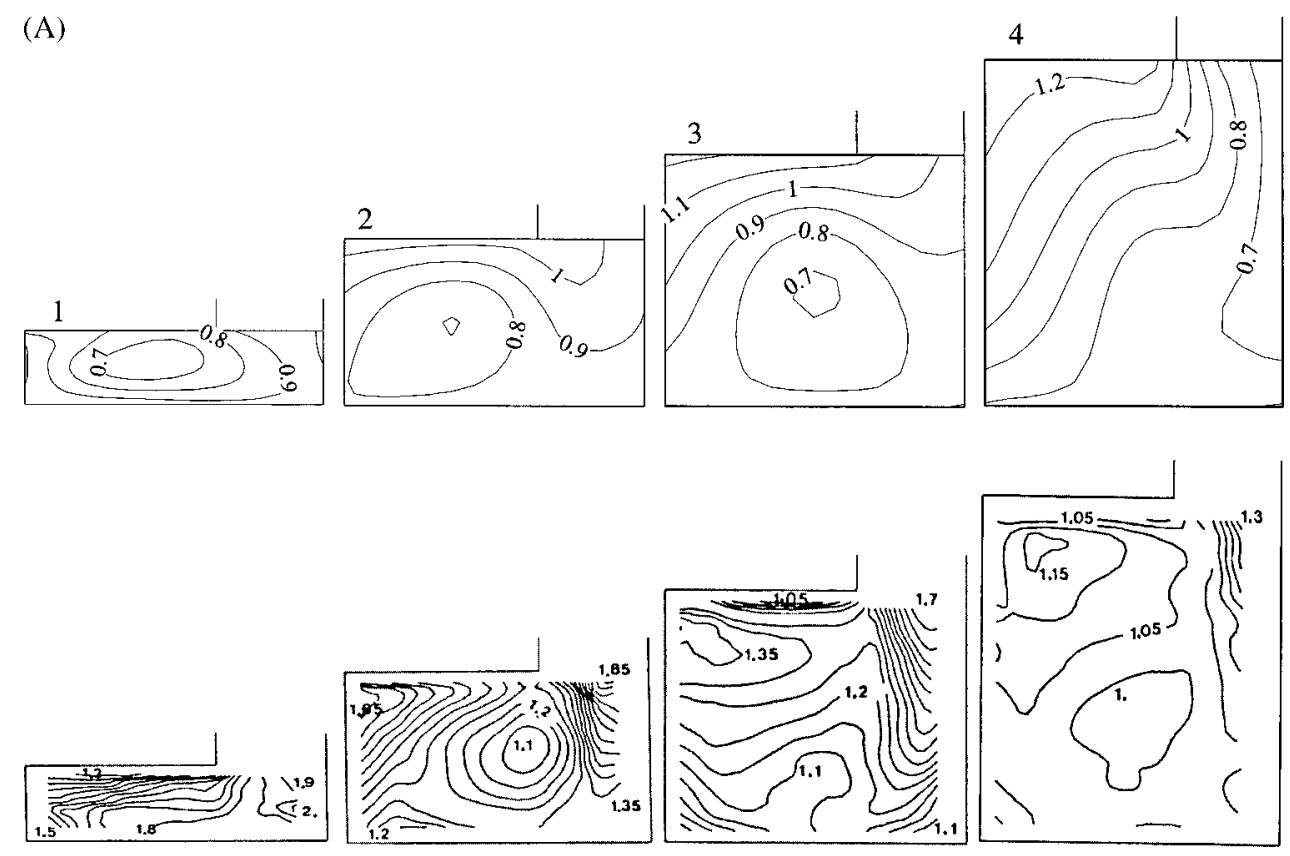

(B)
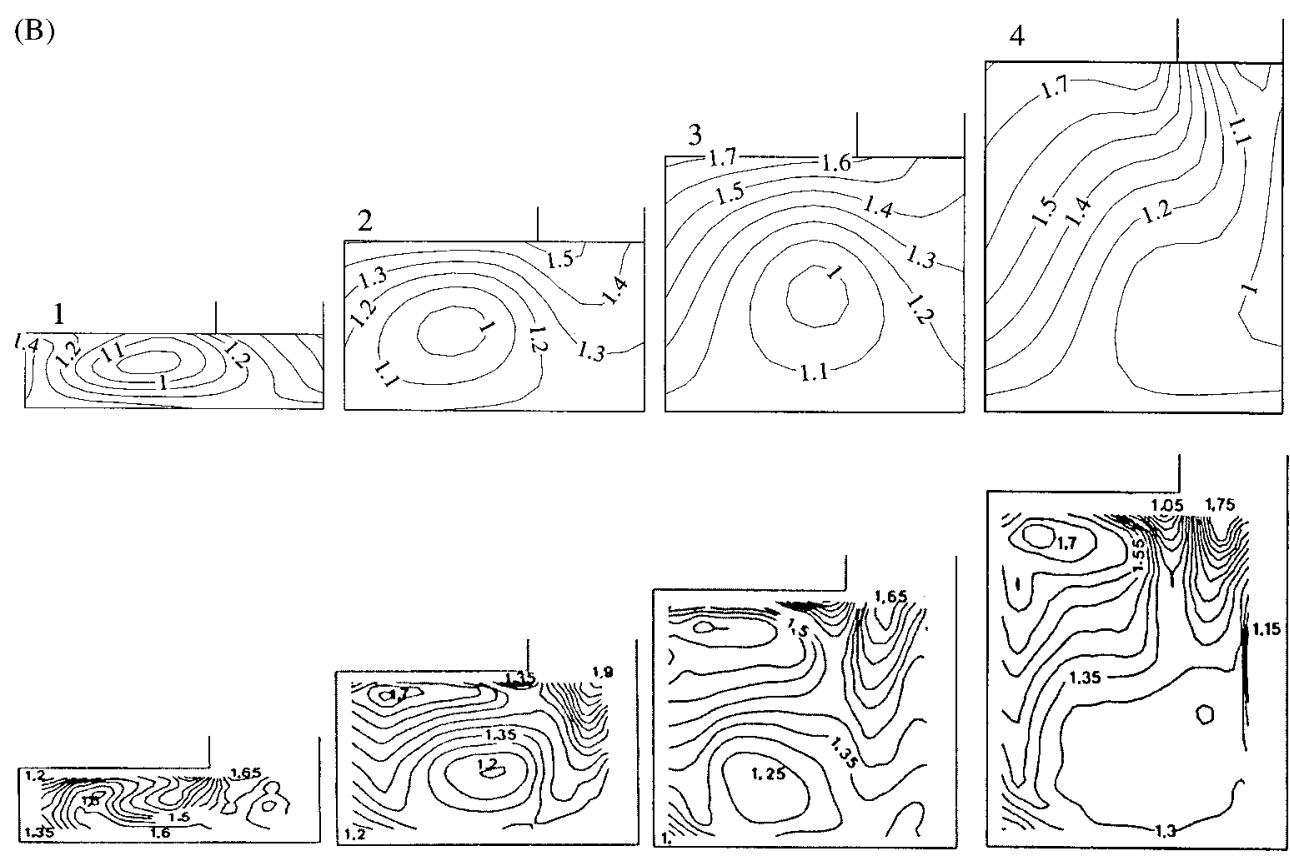

FIGURE 6

(A) Comparison of the through-flow velocity distribution at cross-sections 1, 2, 3, and 4 corresponding to a low flow rate for numerical and experimental studies, recpectively. (B) Comparison of the through-flow velocity distributions at cross-sections 1, 2,3 , and 4, corresponding to a medium flow rate for numerical and experimental studies, respectively. (C) Comparison of the through-flow velocity distribution at cross-sections 1,2,3, and 4 corresponding to a high flow rate for numerical and experimental studies, respectively. (Continued) 

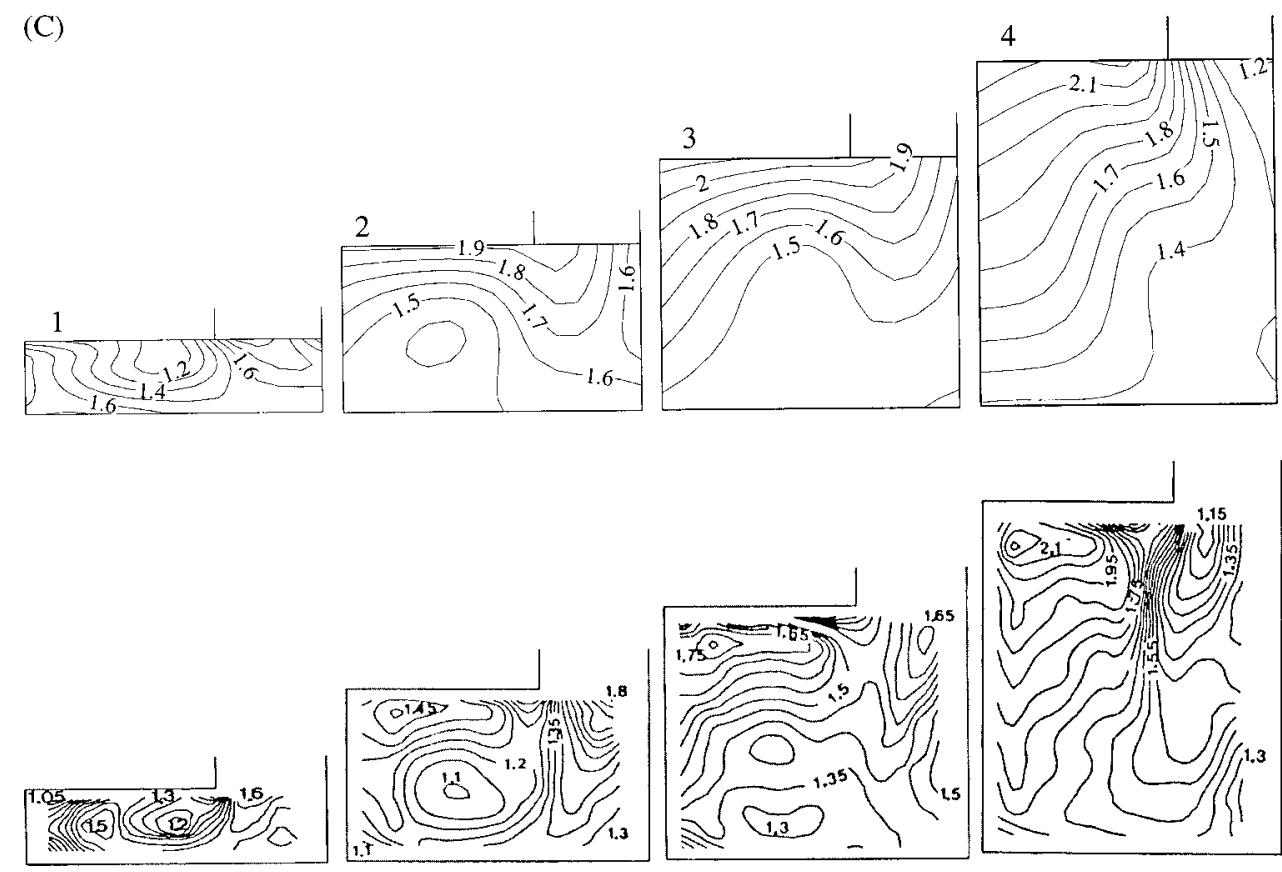

FIGURE 6

(Continued)

Experimental static pressure distribution is not avaliable inside the volute, so the verification of the calculated pressure field could not be performed.

The calculated variations in the static pressure values at the volute inlet are in agreement with the measured variations; therefore, the developed code can be used for studies of impellervolute interaction.

\section{NOMENCLATURE}

\begin{tabular}{|c|c|}
\hline & Pseudospeed sound \\
\hline$\vec{F}, \vec{G}, \vec{H}$ & $\begin{array}{l}\text { Flux vectors of Euler equations in } x, y \text {, and } z \\
\text { directions }\end{array}$ \\
\hline$\vec{U}$ & Solution vector \\
\hline $\mathrm{R}$ & Impeller exit radius \\
\hline$x, y, z$ & Cartesian coordinates \\
\hline$u, v, w$ & Components of flow velocity in $x, y$, and $z$ directions \\
\hline$t$ & Time \\
\hline$p$ & Pressure \\
\hline$\rho$ & Density \\
\hline
\end{tabular}

\section{Subscripts}

$x \quad x$ component

$y \quad y$ component

$z \quad$ Axial component

$0 \quad$ Stagnation conditions

\section{REFERENCES}

Ayder, E., and Van den Braembussche, R. A. 1991. Experimental study of the swirling flow in the internal volute of a centrifugal compressor. ASME Paper 91-GT-7. June 1991, Orlando, Florida, USA.
Ayder, E. 1993. Experimental and numerical analysis of the flow in centrifugal compressor and pump volutes (Phd diss, Gent University and von Karman Institute for Fluid Dynamics).

Ayder, E., Van den Braembussche, R. A., and Brasz, J. J. 1993. Experimental and theoretical analysis of the flow in a centrifugal compressor volute. ASME Journal of Turbomachinery 115:582589.

Ayder, E., and Van den Braembussche, R. A. 1994. Numerical analysis of the three-dimensional swirling flow in centrifugal compressor volutes. ASME Journal of Turbomachinery 116:462468.

Chorin, A. J. 1967. A numerical method for solving incompressible viscous flow problems. Journal of Computational Physics 2:1226.

Elholm, T., Ayder, E., and Van den Braembussche, R. A. 1992. Experimental study of the swirling flow in the volute of centrifugal pump. ASME Journal of Turbomachinery 114:366-372.

Hagelstein, D., Hillewaert, K., Van den Braembussche, R. A., Engeda, A., Keiper, R., and Rautenberg, M. 2000. Experimental and numerical investigation of the flow in a centrifugal compressor volute. ASME Journal of Turbomachinery 122:22-30.

Hubl, H. P. 1975. Beitrag zur berechnungdes spiralgehauses von raialverdichtern $\mathrm{u}$. Vorherbestimmung seines betriebsverhaltens. Technische Universitat Wien, Nr. 7.

Mishina, H., and Gyobu, I. 1978. Performance investigations of largecapacity centrifugal compressors. ASME Paper 78-GT-3. London, England.

Van den Braembussche, R. A., and Hande, B. M. 1990. Experimental and theoretical study of the swirling flow in centrifugal compressor volutes. ASME Journal of Turbomachinery 112:38-43.

Van den Braembussche, R. A., Ayder, E., Hagelstein, D., Rautenberg, M., and Keiper, R. 1999. Improved model for the design and analysis of centrifugal compressor volutes. ASME Journal of Turbomachinery 121:619-625. 

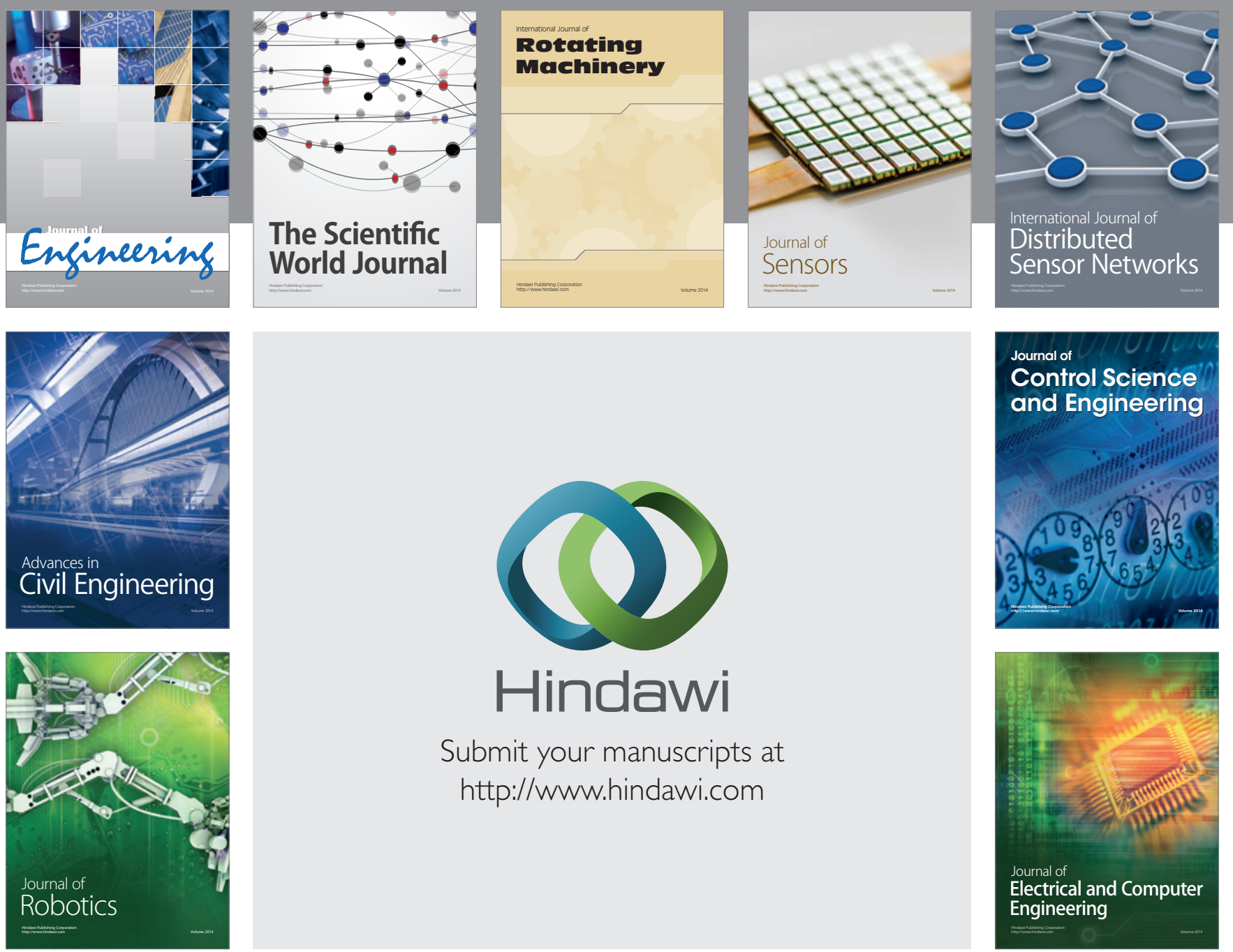

Submit your manuscripts at

http://www.hindawi.com
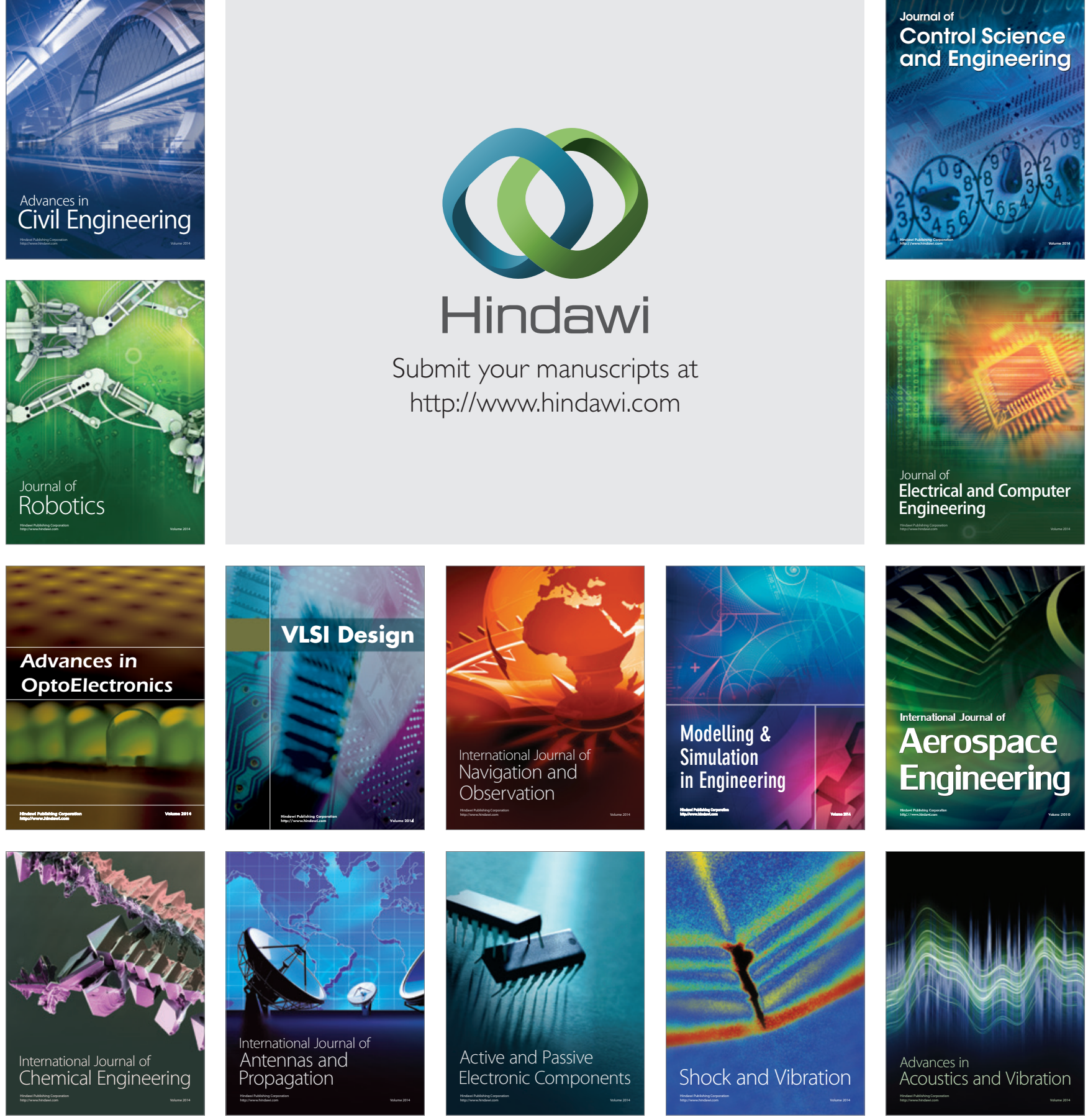